\title{
Experiment and Failure Analysis of Rock-Like Material Affected by Different Excavation Depths
}

\author{
Yuan Tian $\mathbb{D}^{1,2}$ Zhende Zhu, ${ }^{1,2}$ Xinyu Liu $\mathbb{D}^{3},{ }^{3}$ and Yanxin He $\mathbb{D}^{1,2}$ \\ ${ }^{1}$ Key Laboratory of Ministry of Education of Geomechanics and Embankment Engineering, Hohai University, \\ Nanjing 210098, China \\ ${ }^{2}$ Jiangsu Research Center Geotechnical Engineering Technology, Hohai University, Nanjing 10098, China \\ ${ }^{3}$ College of Civil Engineering and Architecture, Zhejiang University of Water Resources and Electric Power, \\ Hangzhou 310018, China
}

Correspondence should be addressed to Yuan Tian; yuantian424@hhu.edu.cn

Received 30 December 2020; Revised 24 January 2021; Accepted 31 January 2021; Published 9 February 2021

Academic Editor: Miao Chen

Copyright (c) 2021 Yuan Tian et al. This is an open access article distributed under the Creative Commons Attribution License, which permits unrestricted use, distribution, and reproduction in any medium, provided the original work is properly cited.

In order to increase the understanding of the strength and failure mechanism of rock mass during tunnel excavation, a series of uniaxial compression tests were conducted on mortar specimen with cracks and holes by using a rock mechanics servo-controlled testing system. And by monitoring the experimental process, the initiation, propagation, and coalescence process of cracks were observed and characterized. According to the experimental results, the influences of the excavation depth on the mechanical parameters and fracture characteristics of mortar specimens with single hole and the ones with single-hole crack were analyzed in detail. In the specimens with single hole, the peak strength decreases with the increase of hole depth, but the peak strain and elastic modulus have no obvious linear correlation with the hole depth. And the position and angle of initial crack change differently with the increase of the hole depth. The position of initial crack moves from the side of the hole to the top of the hole. When the hole depth exceeds $50 \%$, the crack initiation angle is no longer inclined to the axial stress direction, but parallel to the axial stress direction. In the specimens with single prefabricated crack, the wing-shaped secondary cracks are generated at the tip of the precrack, and the antiwing-shaped secondary cracks are generated at the tip when approaching the peak stress. However, in the specimens with single-hole crack, no antiwing-shaped crack appears. And when the hole depth reaches $80 \%$, two wing-shaped cracks appear at the precrack tip. One of the new wing-shaped cracks appears in the direction of the extension line of the precrack.

\section{Introduction}

Since the mining of the earth resources has a long history, coal and mineral resources at shallow depths have gradually been exhausted [1]. Nowadays, deep mining has become very common. As early as the 1980 s, coal mining depths in Poland, Germany, Britain, Japan, and France have exceeded $1000 \mathrm{~m}$. And in China, there are currently 47 coal mines with a depth of more than $1000 \mathrm{~m}[2,3]$. It is very important to understand the strength, failure mechanism, and crack coalescence behavior of rock mass during tunnel excavation to predict the stability of engineering.

Yang [4] conducted a series of uniaxial compression tests on red sandstone specimens with two prefabricated elliptical holes and analyzed the influences of the coplanar angle and ligament angle on the mechanical parameters and fracture process. Wong and Chau [5] conducted uniaxial compression tests on sandstone-like material with two parallel cracks with different dip angles, bridge angles, and friction coefficients. And they have concluded that the typical modes of crack coalescence are shear mode, shear-tension mode, and wing-tension mode. Gratchev et al. [6] studied the effects of the length and width of the crack on the strength of rock specimens. They have found that the strength of the specimen is lower when the crack is longer and wider, and the damage of the specimen is mainly caused by shear cracks. Lajtai et al. [7] observed the rock fracture and failure characteristics by the biaxial compression tests in the 
laboratory. Fakhimi et al. [8] conducted biaxial compression tests on sandstone with single hole to simulate the failure of brittle rock during underground excavation. In this experiment, the axial force and displacement were monitored, and microcracks were detected by acoustic emission technology. Chen et al. $[9,10]$ revealed the failure mechanism of specimens containing nonpersistent joints with various joints inclinations.

Due to the existence of pores, microcracks, grains, and minerals, rock mass is heterogeneous [11]. With the development of modern technology, researchers are increasingly using new technologies to study rock engineering. Researchers have conducted many experimental studies, using optical microscopes [12], the scanning electron microscope [13-15], the acoustic emission detection methods [16-18], the X-ray CT images $[19,20]$, and other different technologies to reveal the fracture process and the failure mechanism of microcrack propagation. Their research shows that the macroscopic fracture behavior and the failure mechanism of rock are closely related to the initiation, growth, propagation, and coalesce of the microcrack. Zhao et al. [21] conducted uniaxial compression tests on granite specimens with single hole and used acoustic emission (AE) spatial location technology to study the evolution of cracks around the hole. Their experimental results show that the tensile stress and compressive stress have an important influence on the fracture evolution process. In order to study the temperature effects on the mechanical properties of rock, Yin et al. [22] conducted uniaxial compression tests on granite specimens with a central hole after high-temperature exposure. Based on the experimental results, they have concluded that the peak strength and elastic modulus first increase with temperature and then decrease. Liu et al. [23] used AE technology and moment tensor (MT) method to analyze the crack propagation process of single-hole granite specimens under uniaxial compression.

In a large number of studies, in order to understand the mechanical properties and fracture characteristics of rock mass affected by excavation, the method of prefabricated hole and crack in rock-like material is usually used in the laboratory. Macroscopically, the circular hole is the excavation section form often used in underground engineering, so it can be used to simulate the tunnel in the rock mass when the underground excavation hole exists [24]. Microscopically, pores and cracks are common defects in natural rock mass [25]. At the same time, the method of artificially prefabricated hole and crack is easier to control the experimental conditions and can increase the stability and reliability of the collected data [26]. Therefore, this paper used mortar specimens with holes and cracks to simulate underground tunnel rock mass. Laboratory uniaxial compression tests were conducted to obtain the strength and deformation characteristics of the tunnel rock mass that change with the vertical load.

\section{Experimental Material and Loading Procedure}

2.1. Preparation of Mortar Specimen. The mechanical properties and deformation characteristics of cement mortar are similar to those of natural rock. Cement mortar is easy to prefabricate crack and hole, so model experiments with similar material can easily simulate the geological characteristics of rock mass in engineering. Compared with field measurement, this method can be used to control a single variable in the laboratory and has the advantages of reliable data and controllable conditions. In order to study the cracking behavior of underground tunnel rock mass under vertical load, the specimens are made of Portland cement and river sand with an appropriate strengthening agent and artificially prefabricated holes and cracks. The particle size of the screened natural river sand is less than $1.25 \mathrm{~mm}$, and the ratio of cement to river sand to water is $1: 0.5: 0.4$. Adding an appropriate amount of additives during the mixing process can make the curing process more stable. After mixing evenly, pour the material into the model, and then insert the mold to prefabricate hole and crack. The advantage of prefabrication is to avoid the original damage caused by violent opening after solidification. The specimens are made of the same batch of materials under the same conditions to avoid differences affecting the experimental results. The completed specimen and schematic diagram are shown in Figure 1.

In order to comprehensively study the process of brittle specimens with composite defects, a variety of composite damage specimens are made for statistical study. As shown in Figure 1, $D$ is the diameter of the hole, and $h$ is the depth of the hole. $D$ of one kind of specimen with single hole is $20 \mathrm{~mm}$. And $D$ of another specimen with single-hole crack is $10 \mathrm{~mm}$. The purpose of reducing the diameter is to observe the subsequent evolution of the cracks around the rock mass during the whole process.

2.2. Loading Procedure. Use the rock mechanics servocontrolled test system RMT-150B to conduct all uniaxial compression tests on the specimens. As shown in Figure 2, RMT-150B mechanics test system is specially designed to test the mechanical properties of engineering materials such as rock and concrete. This instrument can preset test steps and then complete them automatically by the computer. The experimenter can also intervene in the test process and change the control mode and test parameters. After the test, the computer system can calculate the stress-strain curve, elastic modulus, Poisson's ratio, and other results. At the same time, a digital video camera is used to record the crack development process of the specimen. In the test, petrolatum is applied to the top and bottom of the specimen to reduce the influence of lateral friction. 

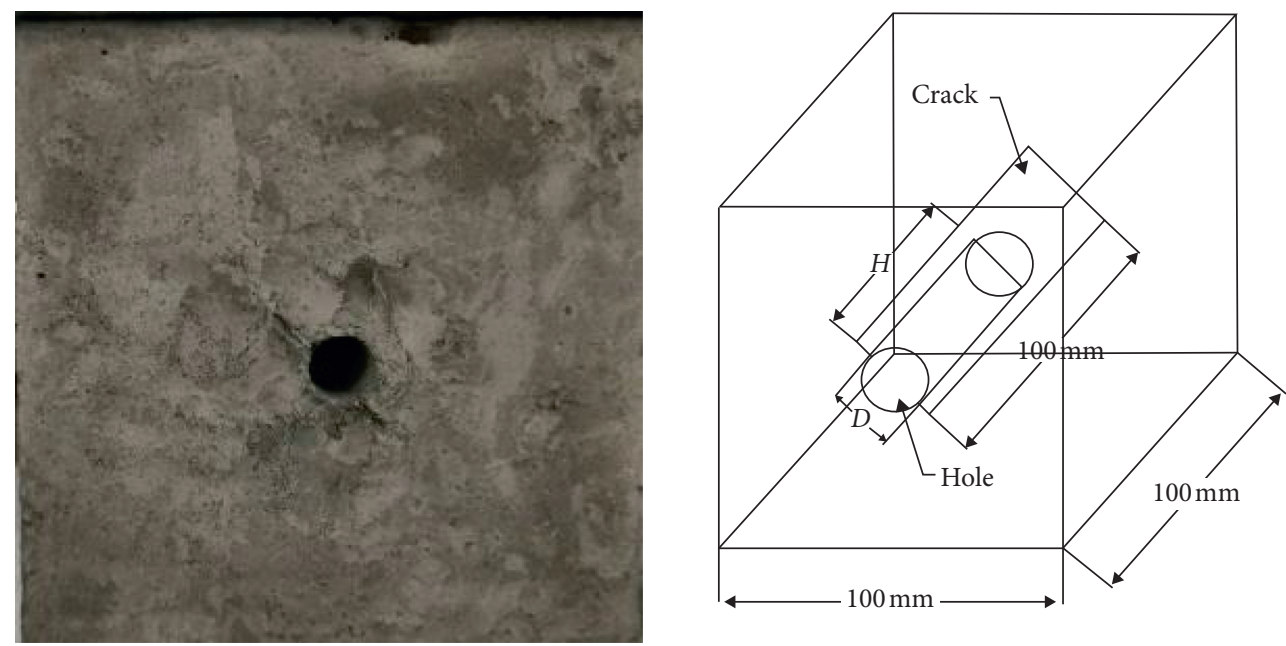

Figure 1: The specimen with single-hole crack and its schematic diagram.
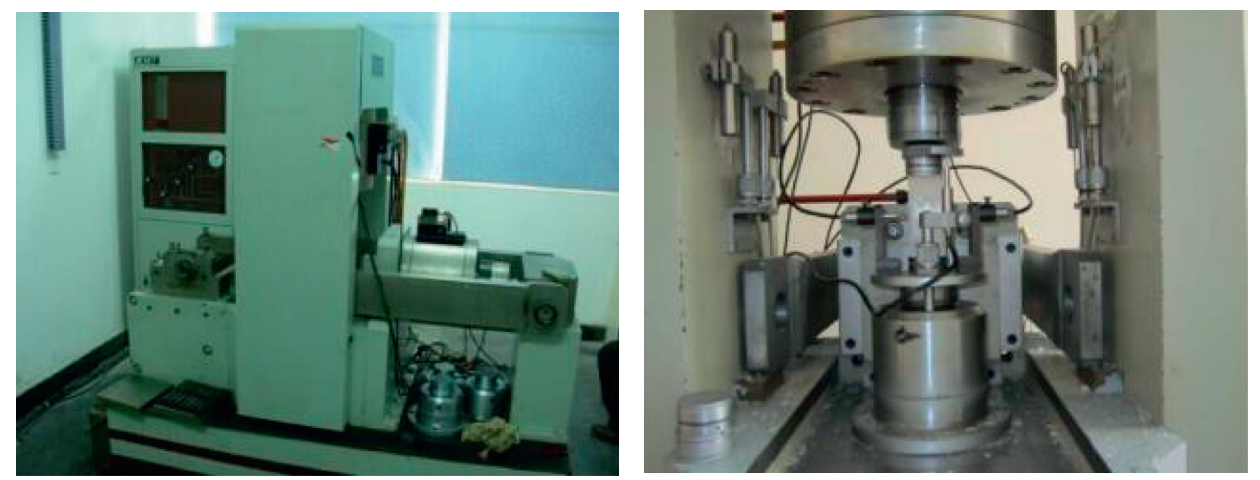

FIGURE 2: Rock mechanics testing system RMT-150B.

\section{Strength Characteristics and Crack Evolution Behavior of Specimen with Single Hole}

As shown in Figure 3, the intact specimen stress-stain curve enters an elastic stage after a brief period of compaction. Then there is obvious plasticity near the peak. When the stress approaches the peak value, the slope of the stressstrain curve gradually decreases, and then small cracks appear on the rock surface. As it approaches the peak, the small cracks gradually expand. After reaching the peak, as the load continues to increase, the specimen suddenly ruptures to form a large crack, and the specimen is damaged and partly falls off. At the same time, the axial stress of the intact specimen drops rapidly after peak strength. Before the peak stress, only a few small cracks appeared. It shows that the tested specimen is sufficiently brittle. On this basis, we prefabricate the specimens with hole and crack to study the influence of hole and crack on the stress and deformation.

\subsection{Strength Characteristics of Specimen with Single Hole.} Figure 4 shows the axial stress-strain curve of the specimen with single hole under uniaxial compression. As shown in the figure, the curve experiences a short compaction stage at the beginning, which is mainly due to the closure of the original fissures or pores in the specimen. Then, elastic deformation begins to dominate the axial stress-strain curve, and the relation between axial stress and axial strain is approximately linear. However, the distinct stress drops are observed in the axial stress-strain curves of the specimens when tensile cracks appear. Through the observation of experiments, each stress drop corresponds to the occurrence or coalescence of one crack in the specimen. We make a detailed analysis of their relationship in the next section of this paper. After several stress drops, the specimen gradually reaches the peak strength and brittle unstable failure occurs as the axial deformation increases. As the hole deepens, the peak stress shows an obvious downward trend, the number of secondary cracks increases, and the fluctuation of small stress drops gradually increased.

Figure 5 shows the change of peak stress and initial cracking stress with the hole depth. According to the statistical data, when the initial hole is relatively shallow, the peak stress decreases by $8 \%-9 \%$ for every $20 \%$ increase in depth. When the hole depth exceeds $40 \mathrm{~mm}$, the peak stress decline begins to accelerate. For every $20 \%$ increase in the hole depth, the peak stress decreases by about $30 \%$. And the results show that when the hole depth is shallow, the initial cracking stress changes more obviously with the hole depth. When the hole depth exceeds $60 \mathrm{~mm}$, the initial cracking 

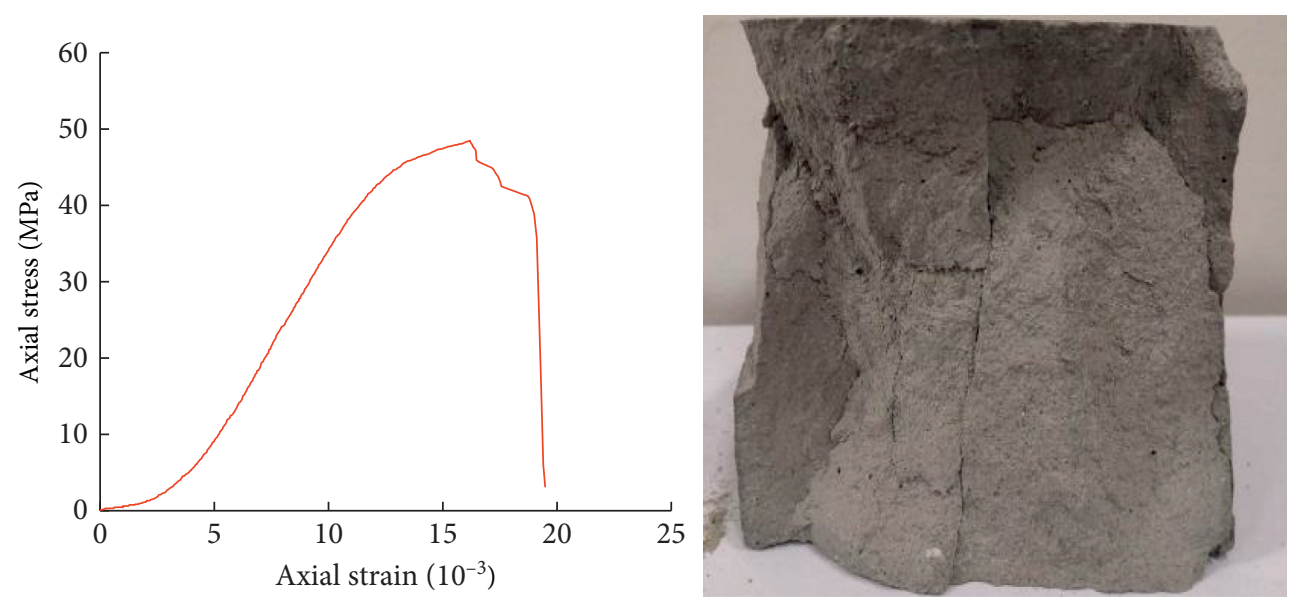

FiguRE 3: Stress-strain curves and failure mode of intact specimens.

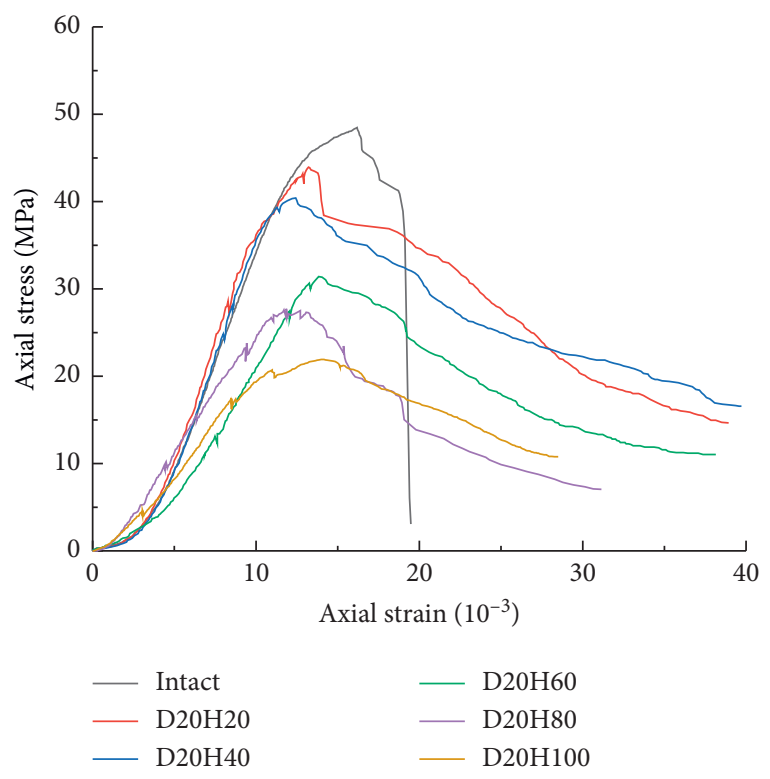

FIgURE 4: The stress-strain curve of specimen with single hole.

strength does not decrease significantly and does not continue to decrease after it drops to $5 \mathrm{MPa}$. As shown in Figure 6, the peak strain changes nonlinearly with the deepening of the hole. The low point of peak strain appears when the hole depth is $40 \mathrm{~mm}$ and $80 \mathrm{~mm}$. And there is no obvious correlation between peak strains. Different from the strain, the elastic modulus has a linear relation with the hole depth. Only in the range of $40 \mathrm{~mm}-60 \mathrm{~mm}$, the elastic modulus decreases significantly, as shown in Figure 7.

3.2. The Crack Evolution Behavior in Specimen with Different Depth Single Hole. Figure 8 shows the final failure modes of specimens with different depth single hole under uniaxial compression. The specimens with different hole depths show different failure modes. The numbers in the figure represent the order in which the cracks appear, and the numbers in the stress-strain curve are the responses when cracks appear in the specimen.

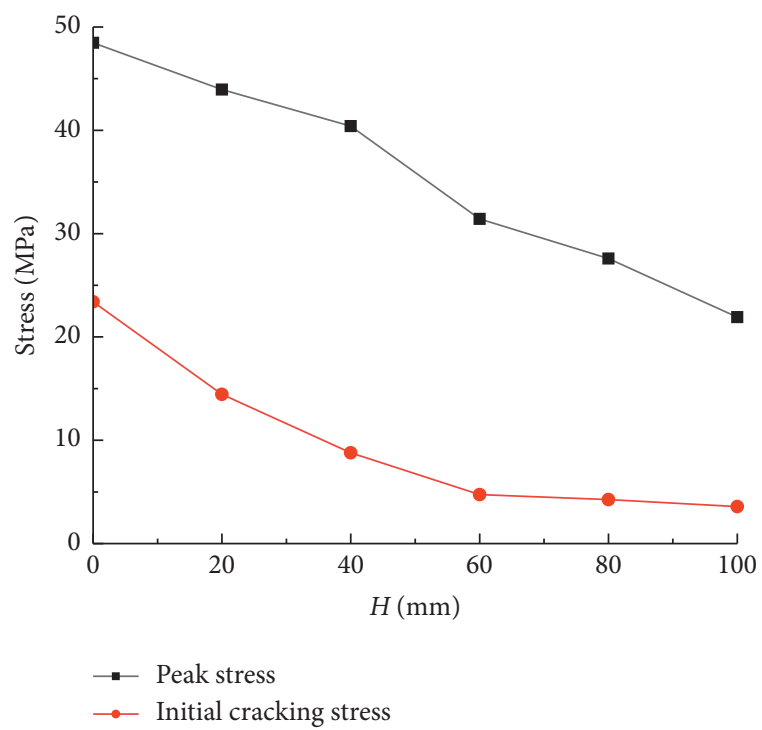

FIGURE 5: The change curve of peak stress and initial cracking stress with hole depth.

As shown in Figure 8(a), in the specimen with $20 \mathrm{~mm}$ depth single hole, the main initiation secondary cracks are two $45^{\circ}$ inclined cracks. The first crack that appears is an almost vertical crack, which is tangent to the single hole, and the tangent point is approximately at the horizontal midpoint line of the single hole. The appearance of this crack has no obvious response to stress and strain, and the overall shape of the curve is in elastic deformation at this time. When No. 2 crack appears, a pause point appears on the stress-strain curve, and No. 2 crack continues to expand at an inclination angle of $45^{\circ}$. At this time, the fragments fall from the hole, and the stress is about $50 \%$ of the peak stress. When No. 2 crack is continuously widened, No. 3 horizontal crack appears, but no response is found in the stress-strain curve when No. 3 crack appeared. When the stress reached $63 \%$ of the peak stress, No. 4 crack appears, resulting in a downward fluctuation of the stress by about $3.3 \%$. At this time, the fragmentation in the hole increases. With the increase of axial load, the vertical directions of No. 5 and No. 


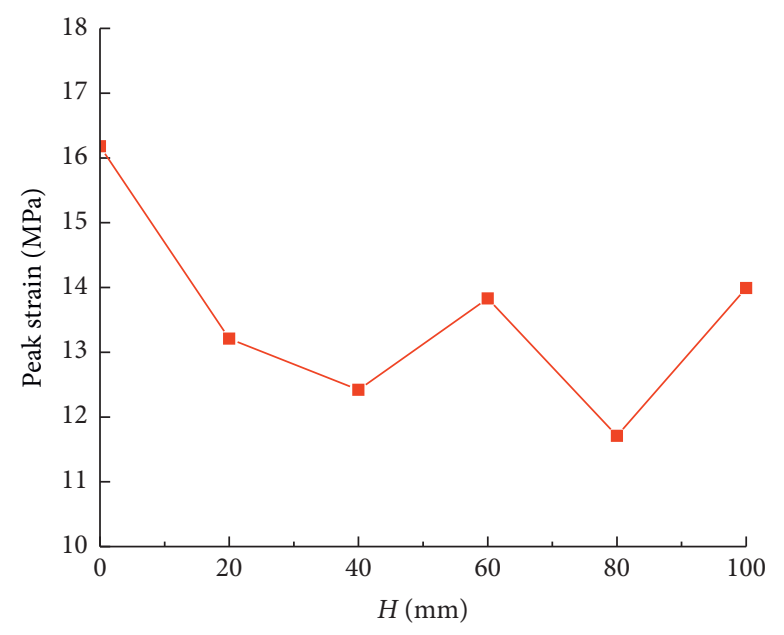

Figure 6: The change curve of peak strain with hole depth.

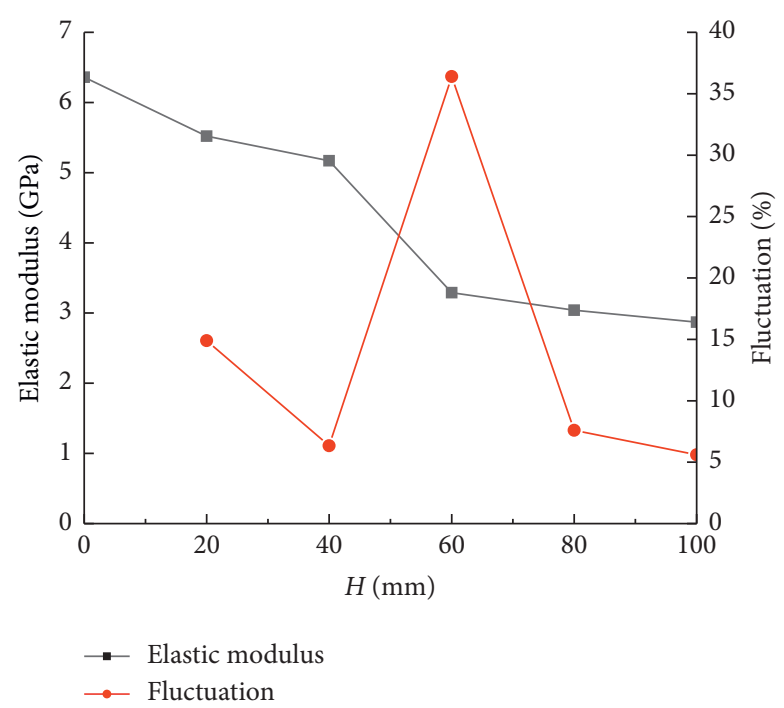

FIgure 7: The change curve of elastic modulus with hole depth.

6 cracks appear. At this time, the slope of stress-strain curve significantly decreases and the specimen enters the plastic stage and reaches the peak stress.

As shown in Figure 8(b), when the hole depth of the specimen with single hole is $40 \mathrm{~mm}$, the initiation cracking sequence of the specimen still starts from two cracks close to the hole. Different from the $20 \mathrm{~mm}$ depth hole, the upper secondary crack of the $40 \mathrm{~mm}$ hole is not directly inclined at $45^{\circ}$ but first cracks vertically and then begins to deviate at an angle of $45^{\circ}$ after a certain distance. When the length and width of No. 2 crack continue to increase and reach $60 \%$ of the peak strength, No. 3 and No. 4 cracks appear successively, and the appearance of No. 4 crack makes the stress drop sharply, as shown in the stress-strain curve figure. Continue to load; when cracks 1, 2, and 4 continue to expand to penetrate, the specimen reaches the peak stress.

As shown in Figure 8(c), the secondary cracks of the specimen with a depth of $60 \mathrm{~mm}$ single hole first appear at the top of the hole. In the early stage of loading, cracks No. 1 and No. 2 appear almost simultaneously. The appearance of No. 1, No. 2, and No. 3 cracks does not cause excessive fluctuations in the stress-strain curve. When the stress reaches $40 \%$ of the peak stress, a longitudinal circular arc crack appears in the specimen, that is, No. 4 crack. The stress continues to increase, and No. 4 crack continues to expand and widen. When it reaches the $4+$ position on the stressstrain curve, the stress drops suddenly. After the longitudinal penetration of crack No. 4 and further widening, crack No. 5 appears, which is close to crack No. 2. Crack No. 2 and crack No.5 cause the material under the hole to break, and the stress of the specimen reached its limit.

As shown in Figure 8(d), the initial cracking mode of the specimen with a depth of $80 \mathrm{~mm}$ single hole is the same as that of the specimen with a depth of $60 \mathrm{~mm}$ single hole. In both cases, the vertical penetration cracks appear on the upper and lower edges of the cracks, and the occurrence time is similar, and only slight fluctuations are caused on the stress-strain curves. Different from the specimen with a 

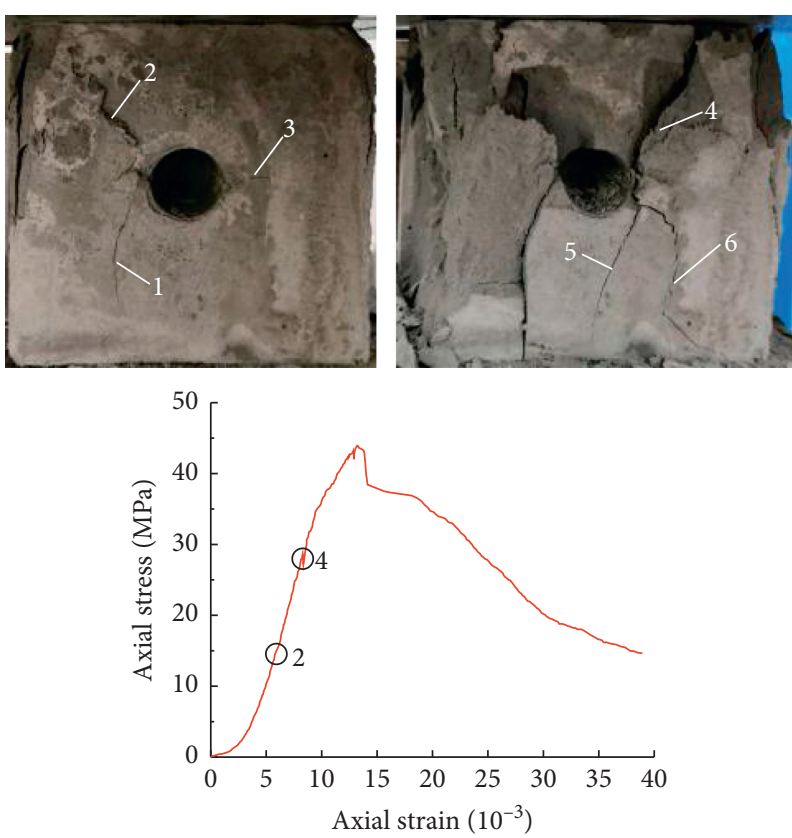

(a)
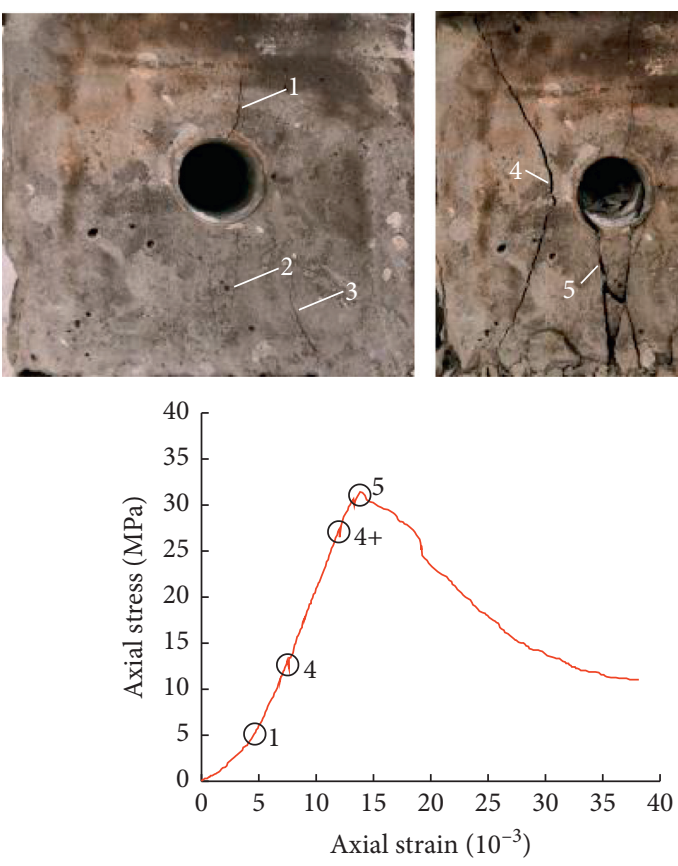

(c)
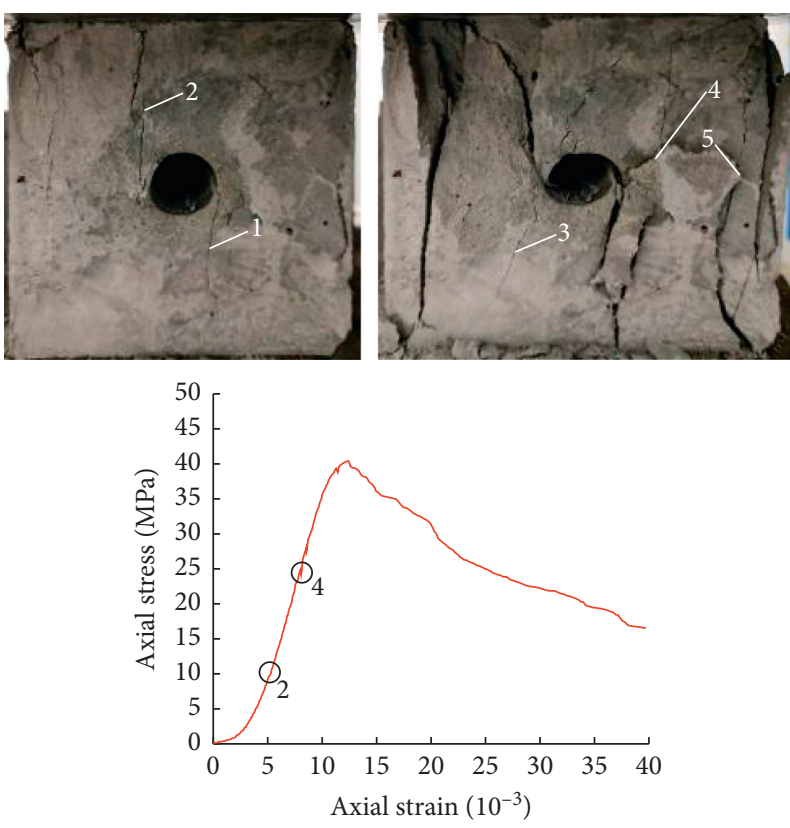

(b)
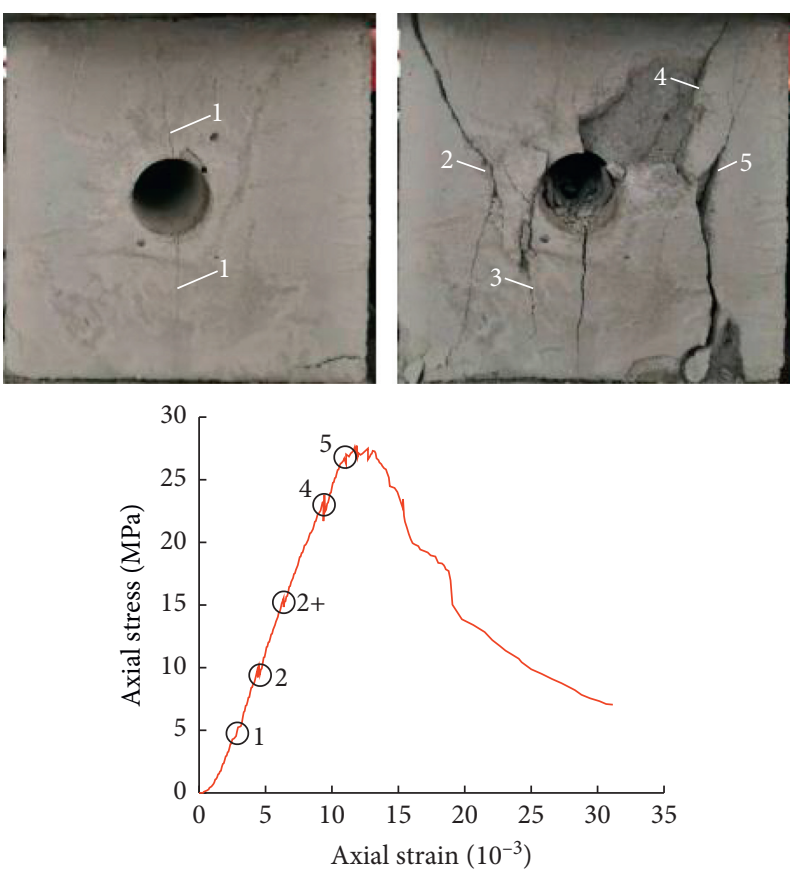

(d)

Figure 8: Continued. 

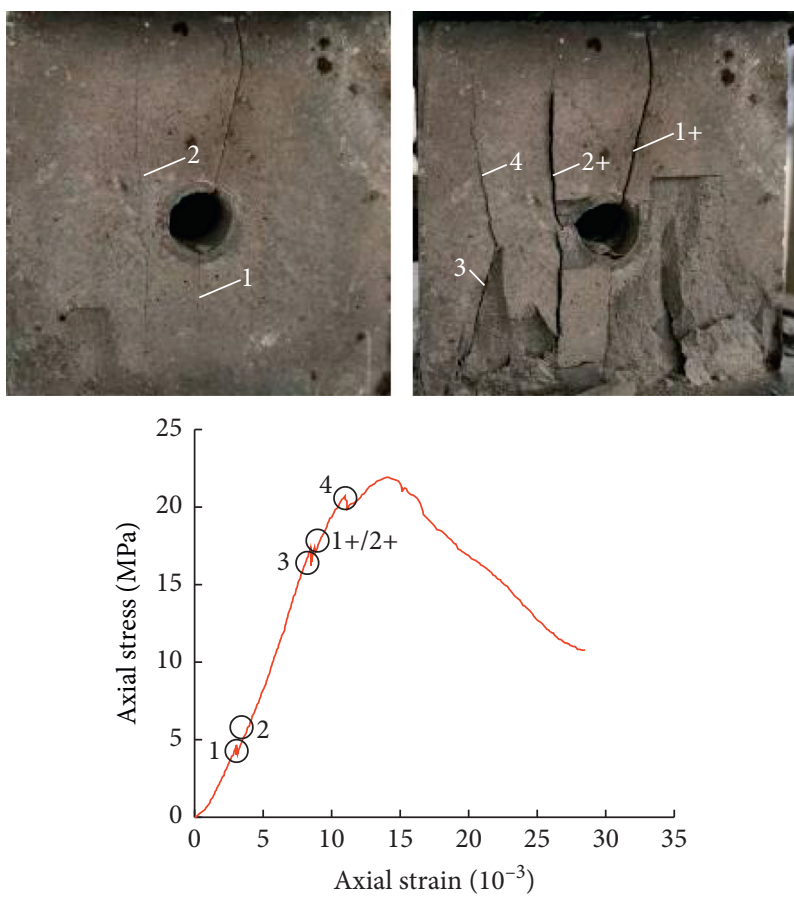

(e)

Figure 8: The stress-strain curves and crack coalescence process of specimen with single hole: (a) $H=20 \mathrm{~mm}$, (b) $H=40 \mathrm{~mm}$, (c) $H=60 \mathrm{~mm}$, (d) $H=80 \mathrm{~mm}$, and (e) $H=100 \mathrm{~mm}$.

depth of $60 \mathrm{~mm}$ single hole, No. 2 crack appears earlier and causes larger stress fluctuations. The crack that causes larger fluctuation is still an arc-shaped crack extending upward and downward, which is No. 2 crack in the figure. When the stress reaches $50 \%$ of the peak stress, the debris in the hole falls off seriously. Because these holes are deep but do not pass through, this structure leads to inconsistent strains in the front and back of the specimen, resulting in a horizontal tensile crack on the back of the specimen. During the continuous loading process, the width of No. 2 circular crack increases continuously. When reaching the $2+$ position of stress-strain curve, stress suddenly fluctuates again, and then No. 3 crack appears. When the stress is close to the peak, No. 4 and No. 5 cracks appear. At this time, the stress state of the specimen is complicated and fluctuates frequently. When No. 5 crack penetrates, the specimen reaches the peak and then breaks.

As shown in Figure 8(e), the specimen is the one with a depth of $100 \mathrm{~mm}$ single hole. The first crack appears in the middle below the hole, and the crack appears immediately after the compaction stage. Subsequently, No. 2 crack appears in the position near the hole within a short time, and No. 2 crack penetrates the specimen vertically. There are also arc-shaped cracks in the specimen with single hole, which are composed of No. 3 and No. 4 cracks, which are far away from the hole and have a small radian. Then, when the stress reaches $80 \%$ of the peak, the crack growth and stress condition become complicated. At the same time, due to the continuous propagation inside the specimen, crack No. 1 and crack No. 2 continue to widen, and finally, crack No. 3 and crack No. 4 appear, forming an arc-shaped crack. After the arc-shaped crack extends upward and downward, the stress reaches the peak value.

In conclusion, according to the analysis of the failure mode, when the hole depth is shallower, cracks first appear around the hole. When the depth of the hole is more than half of the specimen, the initiation secondary cracks occur at the upper and lower positions of the hole. During the loading process, cracks in all the specimens appear and extend from the edge of the hole to the edge of the specimen. And two cracks expanding to the edge form a similar circular arc-shaped crack. The circular arc crack fluctuates greatly in the stress-strain curve. According to the test, when the hole depth is relatively shallow, the debris in the hole falls off slowly and most of them are smaller ones. When the hole reaches a certain depth, the debris turns into larger pieces. When the hole passes through, an additional vertical penetration crack appears near the edge of the hole.

\section{Strength Characteristics and Crack Evolution Behavior of the Specimen with Single- Hole Crack}

4.1. Strength Characteristics of the Specimen with Single-Hole Crack. Many previous studies have focused solely on holeopening tests and crack propagation, but there are relatively few studies on hole-crack compound damage. In this set of tests, prefabricated through-hole cracks are added to singlehole specimens to study the influence of the hole on crack evolution. In this test, the diameter of the hole is $10 \mathrm{~mm}$, and the length of the crack is $30 \mathrm{~mm}$. The hole passes through the 
middle of the crack, and the crack passes through the center point of the hole. The angle between the crack and the vertical load is $45^{\circ}$.

Figure 9 shows the stress-strain curve of the specimen with single-hole crack under uniaxial compression. According to the stress-strain curve, due to the existence of cracks, the peak stress of the specimen decreases significantly compared with the intact specimen. However, with the hole deepens, the declining trend of stress is not particularly obvious; especially in the later stage, the hole has little effect on the peak value of the specimen. Since the existence of hole accelerates the propagation of precracks, the premature appearance of secondary cracks results in a significant decrease in the bearing capacity of specimens.

Figure 10 shows the change of peak stress and initial cracking stress with hole depth. Compared with the specimen with single hole, the peak stress and crack initiation stress of the specimen with single-hole crack decrease to a certain extent. In the early stage, the stress of the specimen with single-hole crack decreases greatly, and the downward trend is slow in the middle and late stages. The first $20 \%$ increase in hole depth leads to a decrease of about $24.6 \%$ in the peak value. In the later stage, the peak stress is reduced by about $15 \%$ for every $20 \%$ increase in depth. However, the crack initiation stress does not decrease significantly with the increase of the hole depth. Due to the existence of precracks, the crack initiation stress is relatively small, and the main controlling factor of the crack initiation stress is precracks, so the hole depth has relatively little effect on the crack initiation stress.

Figure 11 shows the peak stress and peak strain of the specimen. The test shows that the peak stress of the specimen decreases with the increase of the hole depth, but the peak strain does not change linearly with the change of the hole depth. The maximum peak strain occurs when the hole depth is $60 \mathrm{~mm}$, and the minimum strain occurs when the hole depth is $80 \mathrm{~mm}$. As shown in Figure 12, the elastic modulus of the specimen with single-hole crack decreases slowly, but at the hole depth $20 \%-60 \%$, the elastic modulus decreases. According to the stress-strain curve obtained by the test, due to the existence of precracks, the occurrence of secondary cracks can be predicted, and the specimen with single-hole crack does not appear to have a sudden drop in stress during the loading process.

4.2. The Crack Propagation Mechanism of the Specimen with Single-Hole Crack. Figure 13 shows the failure process of the specimen with single-hole crack varying with the hole depth under uniaxial compression. The specimens with different hole depth show different failure modes.

When the specimen contains only through crack but no hole, it is a classic single crack propagation study. As shown in Figure 13(a), the secondary crack first appears at the tip of the precrack, and the initial direction angle of the secondary cracks is about $70^{\circ}$, which is consistent with Shiyu [27] theoretical research. As the load increases, the wing-shaped crack gradually extends to the end of the specimen. When the wing-shaped crack penetrates, classical antiwing-shaped

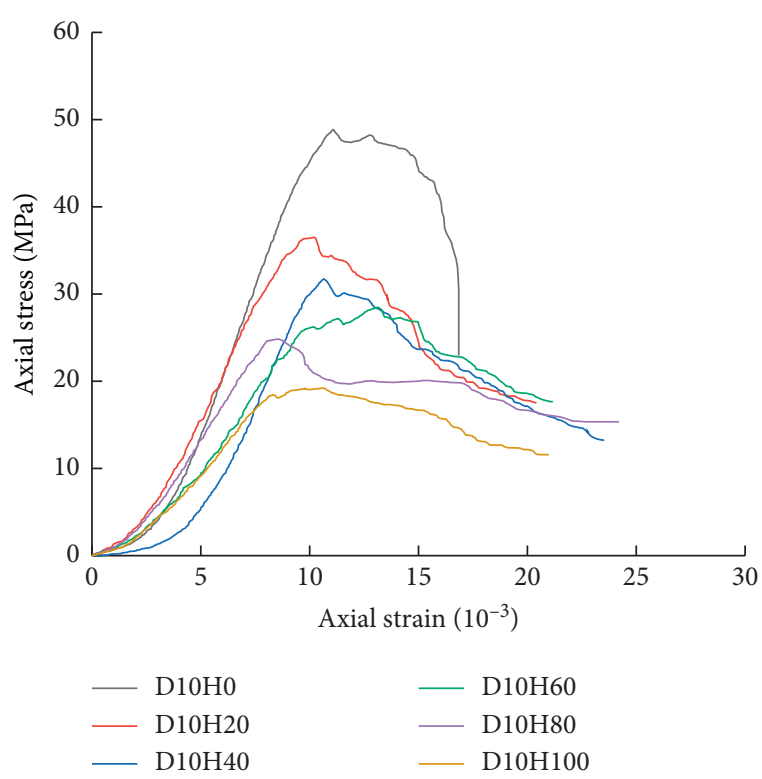

Figure 9: The stress-strain curve of specimen with single-hole crack.

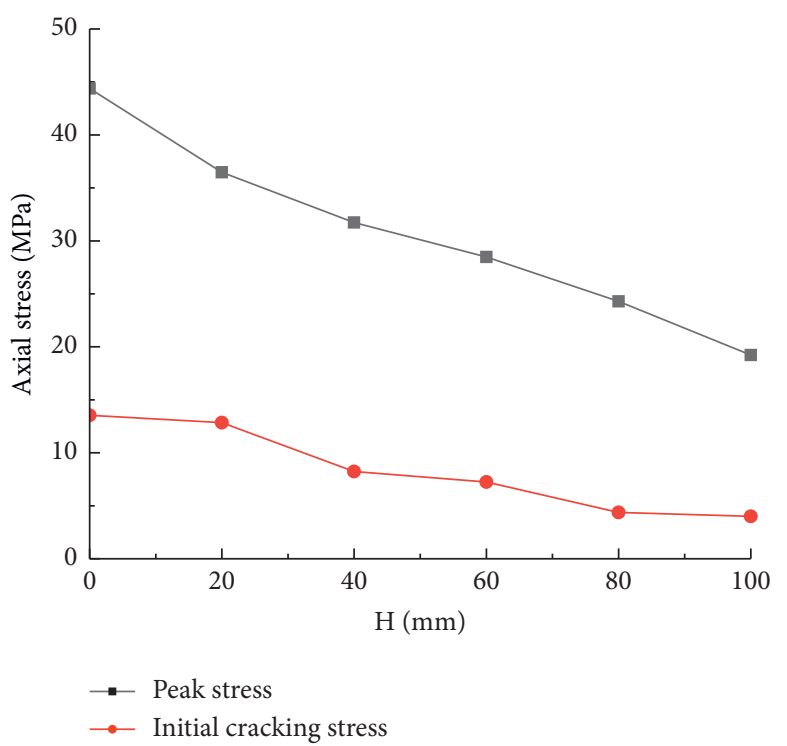

FIgURE 10: The change curve of peak stress and initial cracking stress with hole depth.

crack appears at the upper end of the precrack, which is No. 3 crack in Figure 13(a). After the antiwing-shaped crack appears, the specimen reaches its peak value.

As shown in Figure 13(b), when there is a hole with a depth of $20 \mathrm{~mm}$, the peak stress of the specimen drops substantially by about $25 \%$, and the existence of the hole leads to the emergence of secondary cracks earlier. As shown in the figure, the existence of the hole makes the crack propagation angle larger than the one without hole.

Compared with the specimen without hole, the specimens with $20 \mathrm{~mm}$ depth hole have no antiwing-shaped cracks, and the crack propagation direction changes to the 


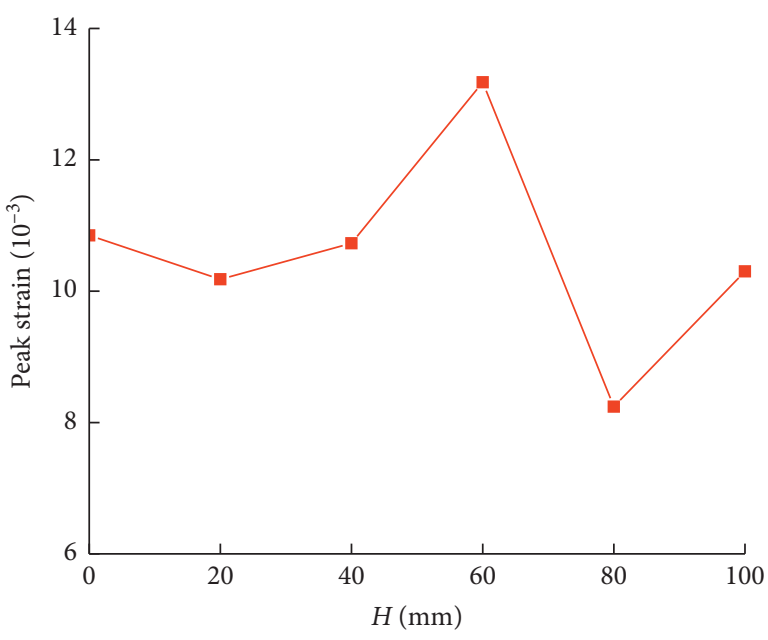

FIgURE 11: The change curve of peak strain with hole depth.

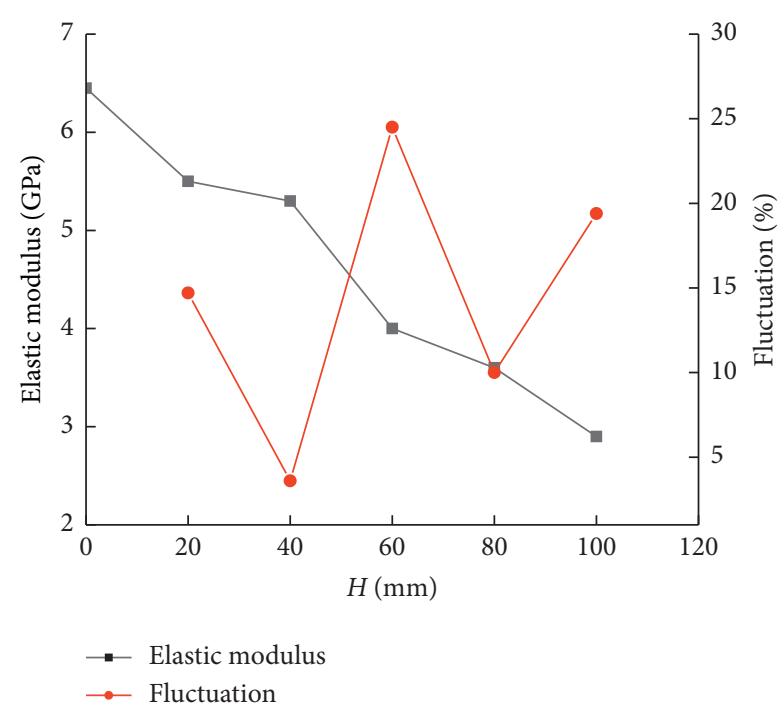

Figure 12: The change curve of elastic modulus with hole depth.

principal stress faster. It is known from the test that, due to the existence of the hole, No. 1 and No. 2 wing-shaped cracks appear after the completion of the compaction stage. As the load increases, the internal damage of the specimen intensifies, causing the width of wing-shaped crack to continue to widen. At the stage close to the peak stress, such as $1+$ and $2+$ positions in the stress-strain curve, the width of the wingshaped crack increases significantly. Since the precrack is a through crack, when the secondary crack extends upward and downward, the specimen has been already divided and the stress reaches its peak.

As shown in Figure 13(c), when the hole depth reaches $40 \mathrm{~mm}$, the peak stress decreases by about $13 \%$. It can be seen from the test that the deepening of the hole makes the angle between the secondary crack and the precrack continue to decrease, and the propagation direction of the upper and lower wing-shaped crack extends to the direction of principal stress more rapidly, as shown in the figure. In this specimen, the hole shows obvious dislocation along the precrack during loading. Due to the dislocation of the hole, No. 1 and No. 2 cracks widen when the stress reaches the peak value.

As shown in Figure 13(d), when the hole depth reaches $60 \mathrm{~mm}$, the expansion angle and morphology are similar to the one of the specimens with a hole depth of $40 \mathrm{~mm}$, but there are more fluctuations on the stress-strain curve. At the lower tip of the precrack, in addition to No. $2 \mathrm{crack}$, another crack appears, which is No. 3 crack in the figure. No. 3 crack penetrates the specimen before the wing-shaped crack. When the stress reaches the peak value, the hole has obvious dislocation along the precrack. When the hole depth reaches $60 \mathrm{~mm}$, the crack growth mode becomes more complicated and the fluctuation of stress-strain curve becomes more frequent.

As shown in Figure 13(e), when the hole depth reaches $80 \mathrm{~mm}$, the test results are similar to the one of the specimens with a hole depth of $60 \mathrm{~mm}$. The upper and lower wing-shaped cracks appear almost simultaneously, and the appearance of secondary cracks has little fluctuation on the stress-strain curve. The same as the specimen with a hole depth of $60 \mathrm{~mm}$, the vertical penetration cracks appear far away from the edge of the hole, which is No. 3 crack in the figure. There are two secondary cracks at the upper and lower ends of the precrack, one of which is a classic wingshaped crack and the other one has a relatively smaller propagation angle.

As shown in Figure 13(f), the depth of the hole reaches $100 \mathrm{~mm}$. At this point, both cracks and holes have penetrated the specimen. The propagation mode of secondary cracks is similar to that of single crack specimen without hole. Wing-shaped cracks appear at the tip of all the precracks. In addition, there is a vertical penetration crack far away from the precrack. However, there is no antiwingshaped crack. Due to the existence of prehole, the initial stress of the secondary crack and the peak stress decrease significantly, and the peak stress is reduced by about $60 \%$.

In conclusion, the initiation position of the specimen with single-hole crack all appears at the tip of the precrack. The existence of the hole and crack prevents the appearance of traditional antiwing-shaped cracks. The crack initiation stress changes little with the depth of the hole, and the existence of precracks greatly affects the crack initiation stress. When the hole depth increased to $60 \mathrm{~mm}$, two wingshaped cracks appear at the tip of the precrack, which accelerated the failure process of the specimen.

\section{Discussion}

Under uniaxial compression, the specimen with single hole and the one with single-hole crack show different changes with hole depth. The detailed data is shown in Tables 1 and 2. Figure 14 shows that the peak stress of the specimen with single-hole crack is generally lower than that of the specimen with single hole. And the effect of the through crack is much greater than that of the hole diameter. The peak strength decreases with the depth of the hole. However, the initial crack stress is relatively complicated. As shown in Figure 15, the specimen with single hole decreases uniformly with the 

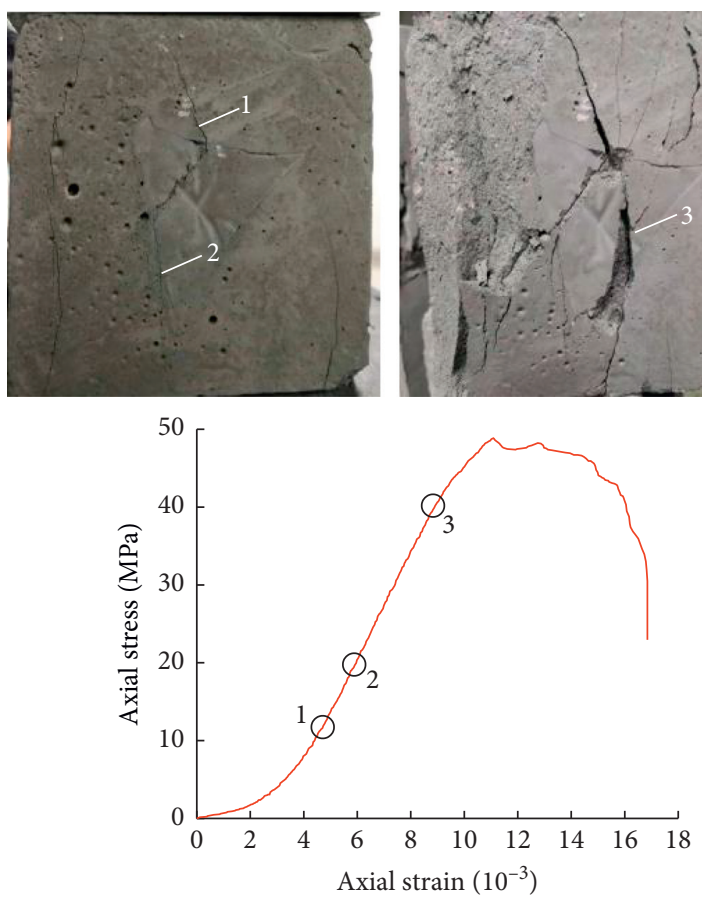

(a)
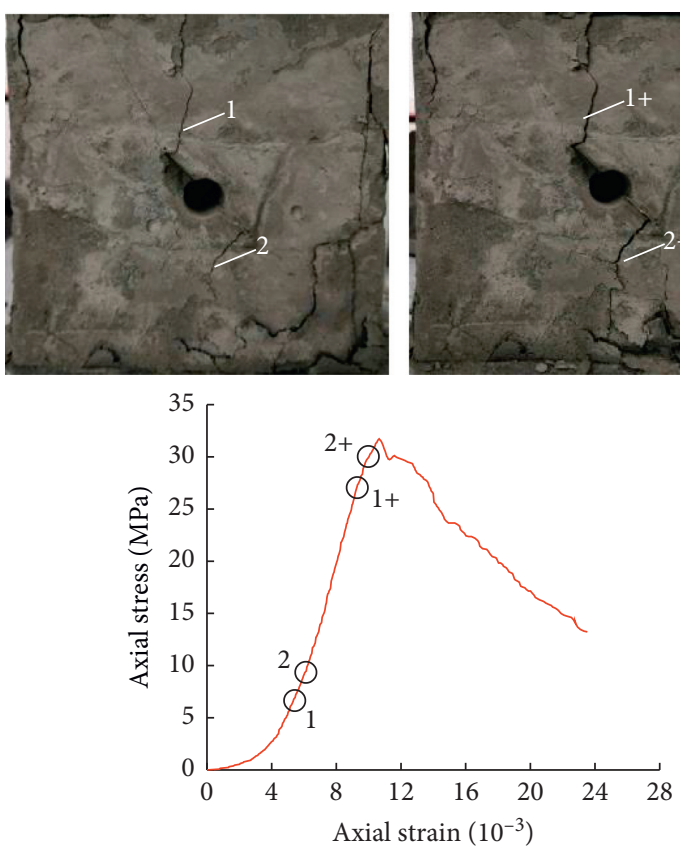

(c)
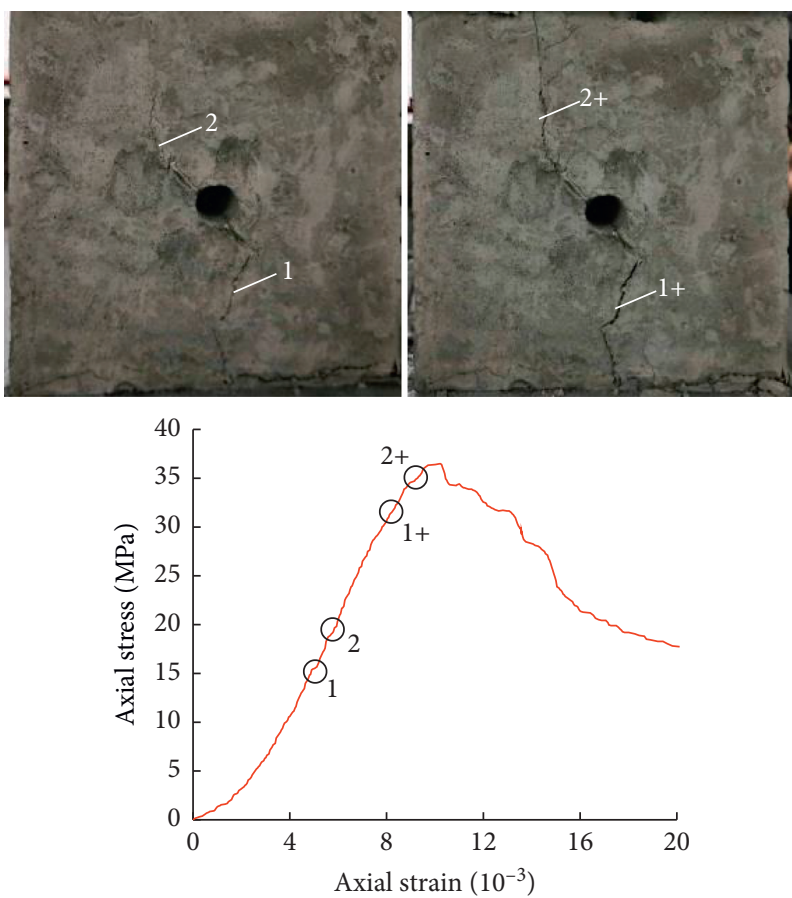

(b)
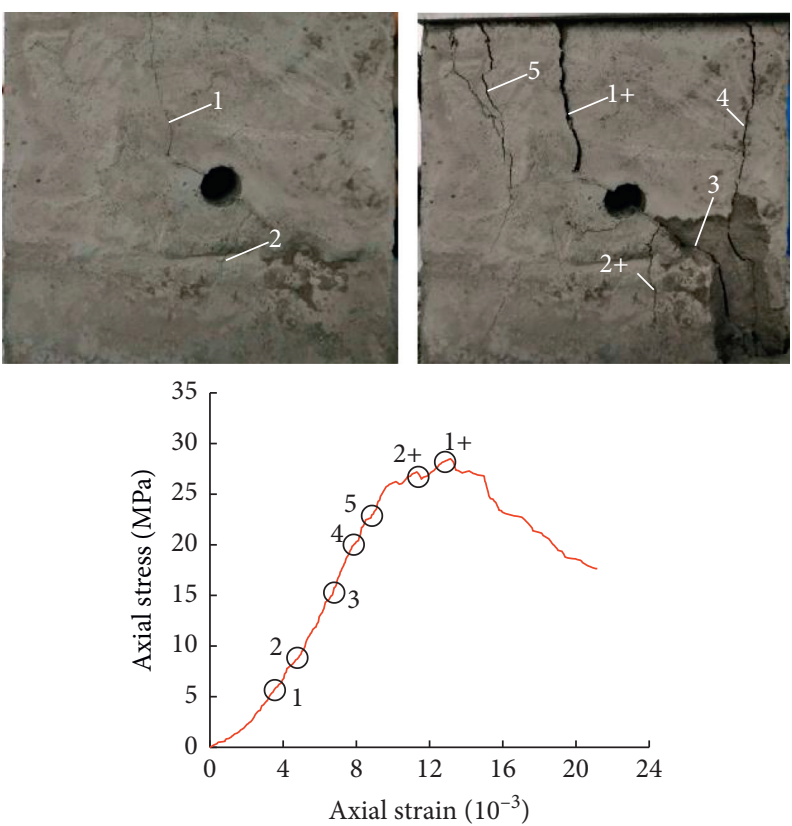

(d)

Figure 13: Continued. 

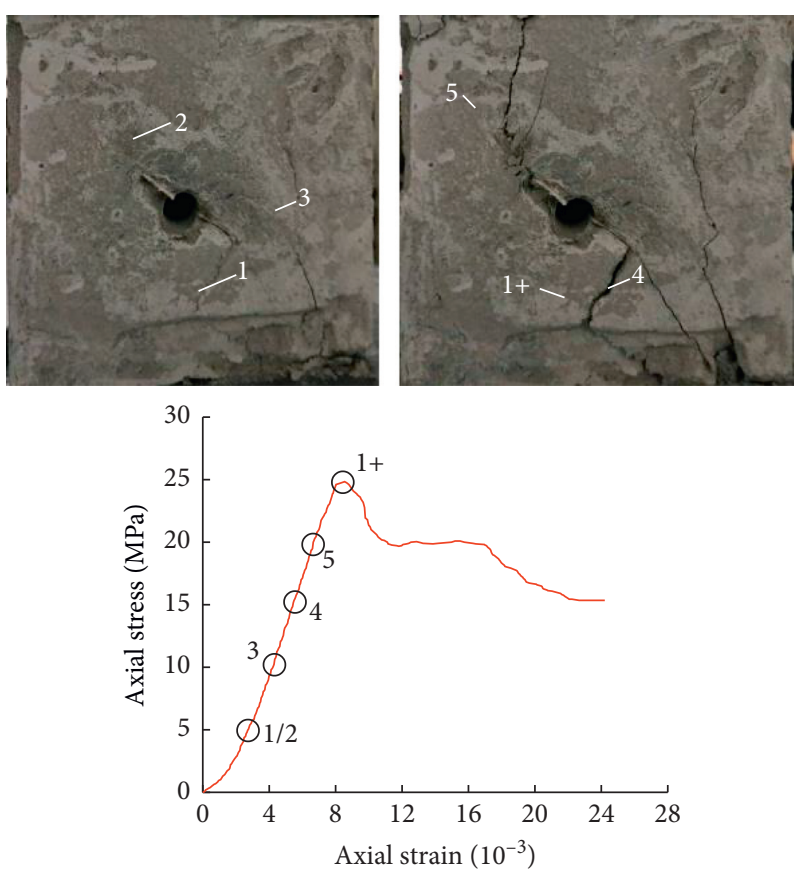

(e)
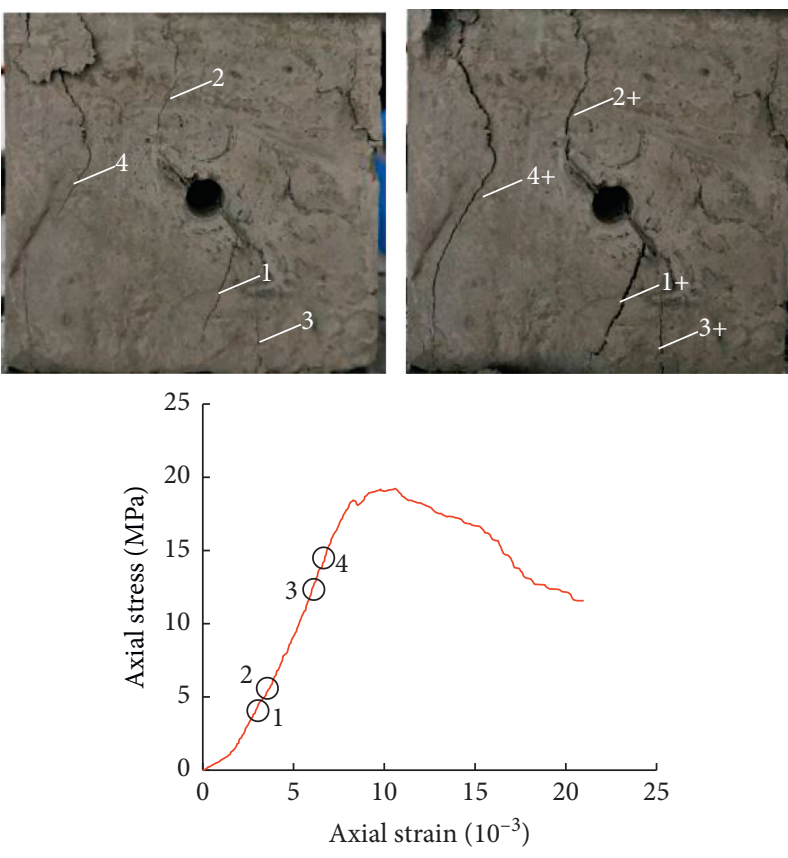

(f)

FIgURE 13: The stress-strain curve and crack coalescence process of specimen with single-hole crack: (a) $H=0 \mathrm{~mm}$, (b) $H=20 \mathrm{~mm}$, (c) $H=40 \mathrm{~mm}$, (d) $H=60 \mathrm{~mm}$, (e) $H=80 \mathrm{~mm}$, and (f) $H=100 \mathrm{~mm}$.

TABLE 1: Uniaxial compression test results of specimen with single hole.

\begin{tabular}{|c|c|c|c|c|c|c|}
\hline Conditions and results & $\mathrm{COHO}$ & $\mathrm{COH} 20$ & $\mathrm{COH} 40$ & $\mathrm{C} 0 \mathrm{H} 60$ & $\mathrm{COH} 80$ & $\mathrm{C} 0 \mathrm{H} 100$ \\
\hline Diameter of hole $(\mathrm{mm})$ & 20 & 20 & 20 & 20 & 20 & 20 \\
\hline Depth of hole (mm) & 0 & 20 & 40 & 60 & 80 & 100 \\
\hline Length of crack (mm) & 0 & 0 & 0 & 0 & 0 & 0 \\
\hline $\mathrm{E}(\mathrm{GPa})$ & 6.34 & 5.52 & 5.17 & 3.29 & 3.04 & 2.87 \\
\hline Initial cracking stress $(\mathrm{MPa})$ & 23.4 & 14.45 & 8.78 & 4.74 & 4.26 & 3.58 \\
\hline Peak stress $(\mathrm{MPa})$ & 48.47 & 43.94 & 40.41 & 31.42 & 27.59 & 21.91 \\
\hline Peak strain $\left(10^{-3}\right)$ & 16.18 & 13.21 & 12.42 & 13.83 & 11.71 & 13.99 \\
\hline
\end{tabular}

TABle 2: Uniaxial compression test results of specimen with single-hole crack.

\begin{tabular}{|c|c|c|c|c|c|c|}
\hline Conditions and results & $\mathrm{C} 30 \mathrm{HO}$ & $\mathrm{C} 30 \mathrm{H} 20$ & $\mathrm{C} 30 \mathrm{H} 40$ & $\mathrm{C} 30 \mathrm{H} 60$ & $\mathrm{C} 30 \mathrm{H} 80$ & $\mathrm{C} 30 \mathrm{H} 100$ \\
\hline Diameter of hole $(\mathrm{mm})$ & 10 & 10 & 10 & 10 & 10 & 10 \\
\hline Depth of hole (mm) & 0 & 20 & 40 & 60 & 80 & 100 \\
\hline Length of crack (mm) & 30 & 30 & 30 & 30 & 30 & 30 \\
\hline Angle of crack $\left({ }^{\circ}\right)$ & 45 & 45 & 45 & 45 & 45 & 45 \\
\hline Elasticity modulus (GPa) & 6.45 & 5.5 & 5.3 & 4 & 3.6 & 2.9 \\
\hline Initial cracking stress & 13.54 & 12.85 & 8.24 & 7.24 & 4.37 & 4.05 \\
\hline Peak stress & 44.38 & 36.48 & 31.73 & 28.48 & 24.29 & 19.23 \\
\hline Peak strain & 10.85 & 10.18 & 10.73 & 13.18 & 8.24 & 10.3 \\
\hline
\end{tabular}

depth of hole. However, the initial crack initiation stress of the specimen with single-hole crack decreases stepwise. When the hole depth exceeds $60 \mathrm{~mm}$, the crack initiation stress of the specimen with single hole is lower than that of the specimen with single-hole crack. As shown in Figure 16, the peak strain changes nonlinearly with the change of hole depth. The changing trend of the two groups of specimens is the same. The maximum value appears at $60 \mathrm{~mm}$ and the minimum value appears at $80 \mathrm{~mm}$. Figure 17 shows the fluctuation of elastic modulus value, and the elastic modulus fluctuates sharply at the hole depth of $60 \mathrm{~mm}$. When the hole depth exceeds $50 \mathrm{~mm}$, a hole appears at the center of gravity of the specimen, resulting in obvious uneven deformation. Combined with the change of the peak stress and peak strain with the hole depth, violent fluctuations occur at the hole depth of $60 \mathrm{~mm}$. 


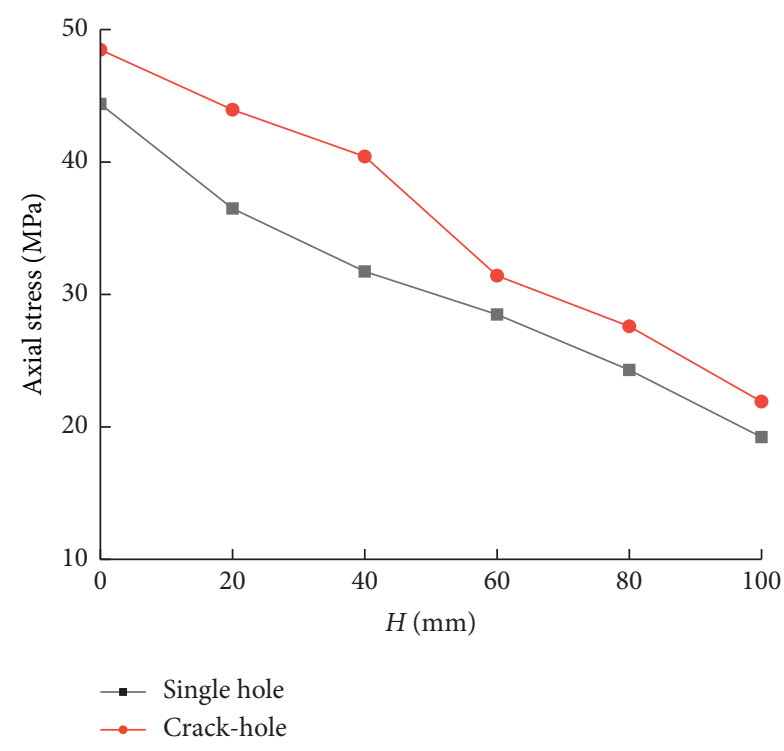

FIgURE 14: The peak stress change with the hole depth.

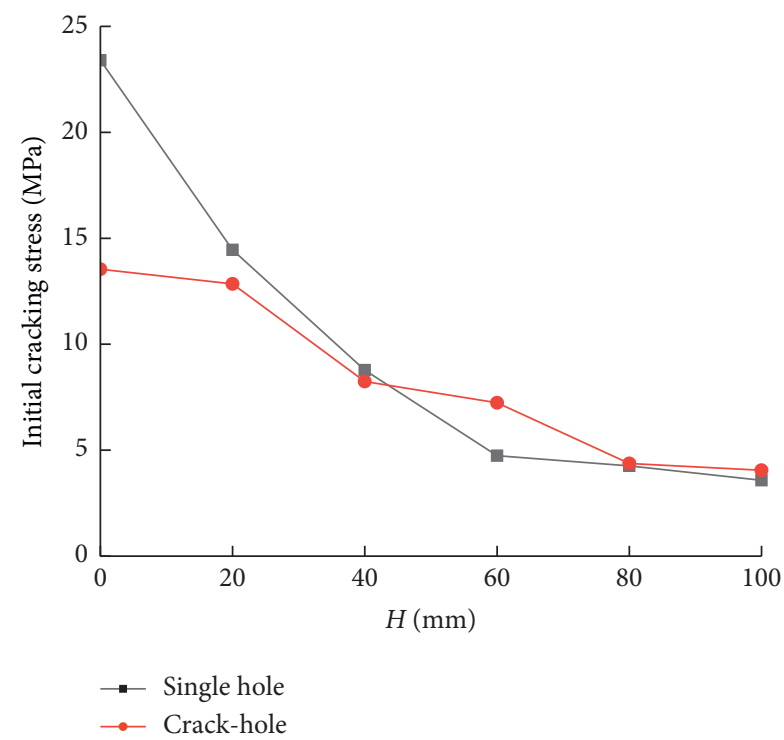

Figure 15: The initial cracking stress change with the hole depth.

According to a large number of studies on crack in rock [28-34], it has been recognized that, due to high-stress concentration, cracks always start from the crack tip. Griffith believes that when the crack end extends for a short length, the release rate of elastic potential energy is greater than the increase rate of surface energy, and the crack is in an unstable state and is bound to expand further. Therefore, in the experiments of this paper, the failure of the sample always occurs preferentially from the prefabricated holes and cracks.

The intact specimen shows obvious shear failure, and the existence of hole and crack leads to complex failure mode of the specimen. In the specimen with single hole, when the hole depth is relatively shallow, the failure mode of the specimen is similar to that of the intact one, which is mainly

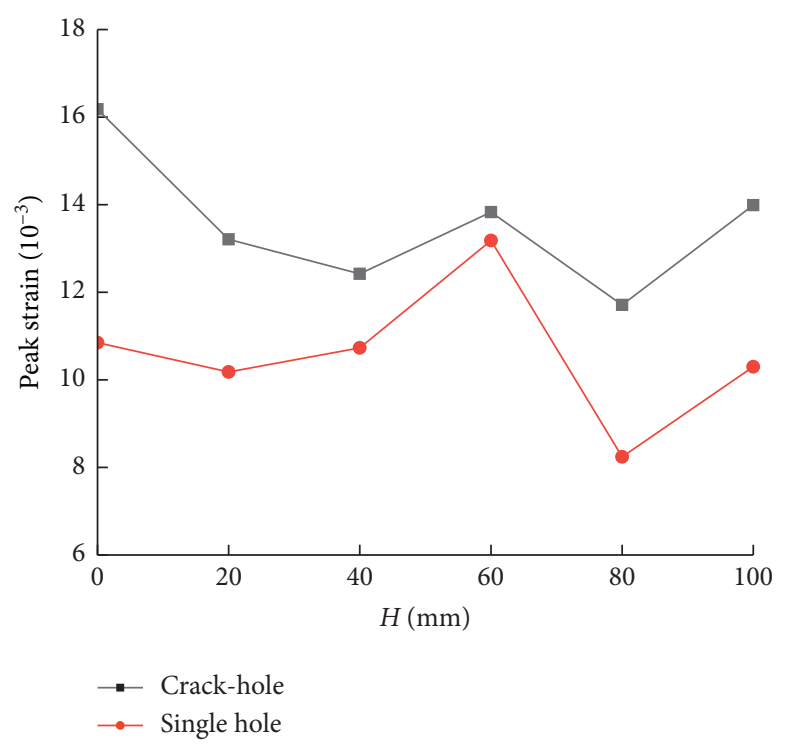

FIGURE 16: The peak strain change curve with the hole depth.

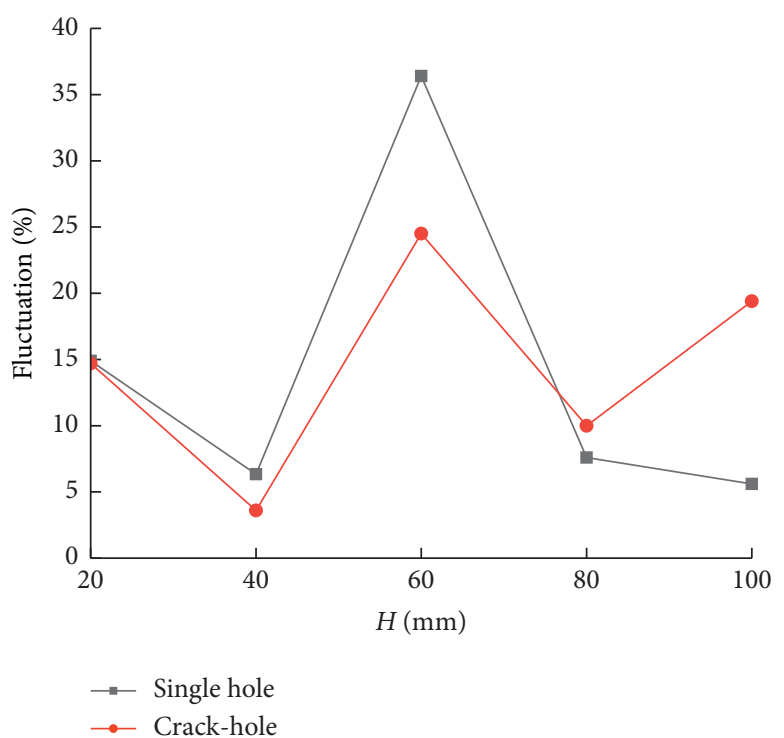

FIgURE 17: The fluctuation ratio of elastic modulus with the hole depth.

shear failure, as shown in Figure 18(a). When the hole depth is more than half of the specimen, the crack initiation point appears directly above the hole, but the shear failure cracks still occur at the edge of the hole and the overall performance is tensile-shear failure, as shown in Figure 18(b). When the hole passes through, the initiation crack still appears above the hole, and the cracks around the hole also show vertical tensile crack. In this case, the crack failure is mainly tensile failure, as shown in Figure 18(c). As shown in Figure 19, the failure mode of the specimen with through crack shows obvious predictability during uniaxial compression. With the deepening of the hole depth, the initial crack initiation point of secondary cracks appears in a shear crack mode from the tip of the precrack. During the loading process, the secondary cracks gradually turn to the principal stress 

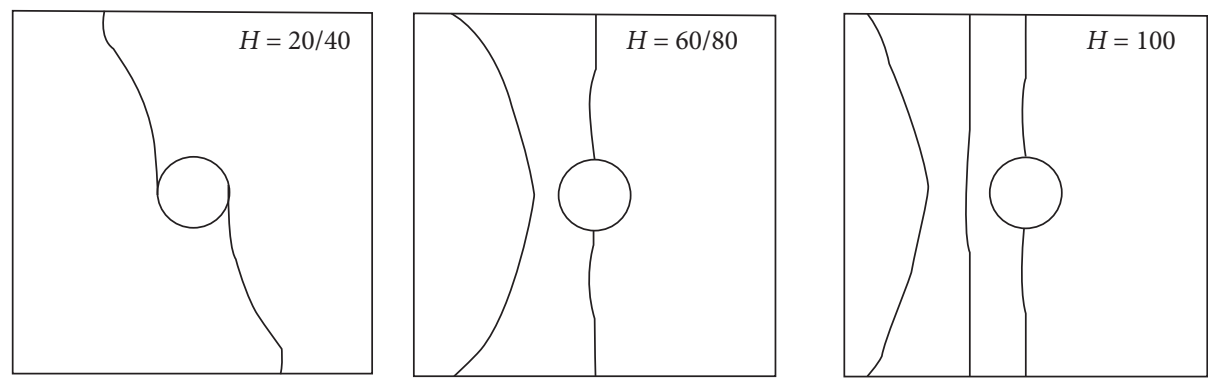

FIgURE 18: Failure diagram of specimen with single hole: (a) $H=20 / 40 \mathrm{~mm}$, (b) $H=60 / 80 \mathrm{~mm}$, and (c) $H=100 \mathrm{~mm}$.
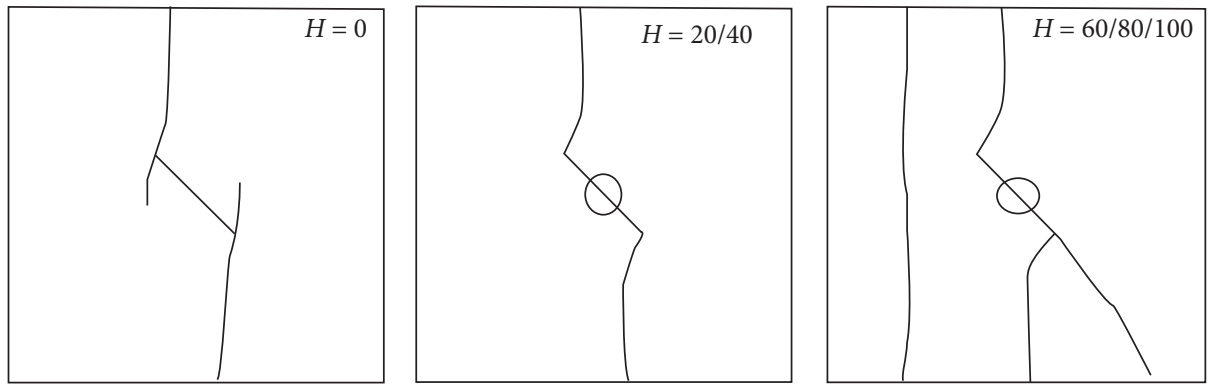

FIGURE 19: Failure diagram of specimen with single-hole crack: (a) $H=0 \mathrm{~mm}$,

(b) $H=20 / 40 \mathrm{~mm}$, and (c) $H=60 / 80 / 100 \mathrm{~mm}$.

direction, showing obvious tensile failure. In addition, the existence of precrack leads to a simple failure mode, and the occurrence of cracks also shows predictability. The occurrence of cracks does not show excessive stress drop on the stress-strain curve.

\section{Conclusions}

(1) The prefabricated hole and crack greatly reduce the mechanical parameters of the mortar specimen under uniaxial compression. In the specimen with single hole, the peak strength has an obvious linear correlation with the hole depth. And there is also a significant correlation between the crack initiation stress and the hole depth. In the specimen with single-hole crack, the hole depth has a relatively small effect on the crack initiation stress, while the through crack plays a major role in the secondary crack initiation. The peak strain and elastic modulus have no obvious relation with the depth of the hole.

(2) The crack initiation, propagation, and coalescence of the specimens are observed by using photographic monitoring. When the hole depth of the specimen with single hole is relatively shallow, the main crack is shear failure from the edge of the hole at an inclination angle of nearly $45^{\circ}$. It is similar to the failure mode of the intact specimen. All cracks extend outward at a certain inclination angle on both sides of the hole. When the hole depth reaches $60 \%$, the initial crack appears directly above or directly below the hole, and then a new crack appears at the edge of the hole and extends outward at a certain angle.
While loading is close to the peak strength, large pieces of debris fall from the hole. However, the initiation cracks in the specimen with single-hole crack appear at the tip of the precrack, and the classic antiwing-shaped cracks do not appear. All wingshaped cracks deflect in the direction of principal stress. When the hole depth reaches $60 \%$, two wingshaped cracks appear at the tip of the precrack. And when the strength is close to the peak value, the hole slips obviously, and the debris falling from the hole is small.

(3) In the process of crack propagation in the specimen with single hole, the appearance of the crack is relatively sudden and not easy to be predicted. The appearance of the crack leads to a sharp drop in stress, which is especially obvious when the hole is deep. However, in the specimen with single-hole crack, due to the existence of crack, the secondary crack is easier to predict and relatively simple. And the crack of specimen with single hole has relatively little interference to the stress.

\section{Data Availability}

The raw/processed data required to reproduce these findings cannot be shared at this time as the data also forms part of an ongoing study.

\section{Conflicts of Interest}

The authors declare that there are no conflicts of interest regarding the publication of this paper. 


\section{Acknowledgments}

This research work was partially carried out with financial support from the National Natural Science Foundation of China (NSFC, Grant no. 51878249), the Natural Science Foundation of Jiangsu Province (no. BK20161508), the Postgraduate Research and Practice Innovation Program of Jiangsu Province (2018B661X14), and the NSFC key fund projects (no. 41831278).

\section{References}

[1] P. G. Ranjith, J. Zhao, M. Ju, R. V. S. De Silva, T. D. Rathnaweera, and A. K. M. S. Bandara, "Opportunities and challenges in deep mining: a brief review," Engineering, vol. 3, no. 4, pp. 546-551, 2017.

[2] H. Xie, "Quantitative definition and investigation of deep mining," Journal of China Coal Society, vol. 40, no. 1, pp. 1-10, 2015.

[3] H. Xie, "Research framework and anticipated results of deep rock mechanics and mining theory," Advanced Engineering Sciences, vol. 49, no. 2, pp. 1-16, 2015.

[4] S.-Q. Yang, Y.-H. Huang, W.-L. Tian, and J.-B. Zhu, "An experimental investigation on strength, deformation and crack evolution behavior of sandstone containing two oval flaws under uniaxial compression," Engineering Geology, vol. 217, pp. 35-48, 2017.

[5] R. H. C. Wong and K. T. Chau, "Crack coalescence in a rocklike material containing two cracks," International Journal of Rock Mechanics and Mining Sciences (Oxford, England: 1997), vol. 35, no. 2, pp. 147-164, 1998.

[6] I. Gratchev, D. H. Kim, and C. K. Yeung, "Strength of rocklike specimens with pre-existing cracks of different length and width," Rock Mechanics and Rock Engineering, vol. 49, no. 11, pp. 4491-4496, 2016.

[7] E. Z. L. V. Lajtai, "The collapse of cavities," International Journal of Rock Mechanics \& Mining Sciences \& Geomechanics Abstracts, vol. 12, no. 4, pp. 81-86, 1975.

[8] A. Fakhimi, F. Carvalho, T. Ishida, and J. F. Labuz, "Simulation of failure around a circular opening in rock," International Journal of Rock Mechanics and Mining Sciences, vol. 39, no. 4, pp. 507-515, 2002.

[9] M. Chen, S.-Q. Yang, P. G. Ranjith, and Y.-C. Zhang, "Cracking behavior of rock containing non-persistent joints with various joints inclinations," Theoretical and Applied Fracture Mechanics, vol. 109, Article ID 102701, 2020.

[10] C. Zang, M. Chen, G. Zhang, K. Wang, and D. Gu, "Research on the failure process and stability control technology in a deep roadway: numerical simulation and field test," Energy Science \& Engineering, vol. 8, no. 7, pp. 2297-2310, 2020.

[11] J. C. Jaeger, Fundamentals of Rock Mechanics, Blackwell Pub, Malden, MA, USA, 2007.

[12] W. R. Wawersik and W. F. Brace, "Post-failure behavior of a granite and diabase," Rock Mechanics, vol. 3, no. 2, pp. 61-85, 1971.

[13] J. Goral, M. Deo, J. McLennan, H. Huang, and E. Mattson, "Macro- and micro-compression testing of shales," Journal of Petroleum Science and Engineering, vol. 191, Article ID 107034, 2020.

[14] Y. Xia, "Micro-pore characteristics and methane adsorption properties of common clay minerals by electron microscope scanning," Acta Petrolei Sinica, vol. 33, no. 2, pp. 249-256, 2012 .
[15] A. Keneti and B.-A. Sainsbury, "Characterization of strainburst rock fragments under a scanning electron microscopean illustrative study," Engineering Geology, vol. 246, no. 246, pp. 12-18, 2018.

[16] Z. Guo, R. Luo, T. Li, and G. Zou, "Influence of size effect on acoustic emission characteristics of rock under uniaxial compression," AIP Conference Proceedings, vol. 1890, no. 1, 2017.

[17] Z. W. M. Yunpeng, "Acoustic emission characteristics of rocks with different brittleness," Lithologic Reservoirs, vol. 29, no. 04, pp. 124-130, 2017.

[18] G.S.J.D.M., "Microcrack formation and material softening in rock measured by monitoring acoustic emissions," International Journal of Rock Mechanics \& Mining Ences \& Geomechanics Abstracts, vol. 30, no. 1, pp. 11-24, 1993.

[19] M. Wang, J. Xie, F. Guo, Y. Zhou, X. Yang, and Z. Meng, "Determination of NMR T2 cutoff and CT scanning for pore structure evaluation in mixed siliciclastic-carbonate rocks before and after acidification," Energies, vol. 13, no. 6, p. 1338, 2020.

[20] T. Akai, M. J. Blunt, and B. Bijeljic, "Pore-scale numerical simulation of low salinity water flooding using the lattice Boltzmann method," Journal of Colloid and Interface Science, vol. 566, pp. 444-453, 2020.

[21] X.-d. Zhao, H.-x. Zhang, and W.-c. Zhu, "Fracture evolution around pre-existing cylindrical cavities in brittle rocks under uniaxial compression," Transactions of Nonferrous Metals Society of China, vol. 24, no. 3, pp. 806-815, 2014.

[22] Q. Yin, H.-W. Jing, and T.-T. Zhu, "Experimental study on mechanical properties and cracking behavior of pre-cracked sandstone specimens under uniaxial compression," Indian Geotechnical Journal, vol. 47, no. 3, pp. 265-279, 2017.

[23] J.-p. Liu, Y.-h. Li, S.-d. Xu, S. Xu, C.-y. Jin, and Z.-s. Liu, "Moment tensor analysis of acoustic emission for cracking mechanisms in rock with a pre-cut circular hole under uniaxial compression," Engineering Fracture Mechanics, vol. 135, pp. 206-218, 2015.

[24] Y.-H. Huang, S.-Q. Yang, P. G. Ranjith, and J. Zhao, "Strength failure behavior and crack evolution mechanism of granite containing pre-existing non-coplanar holes: experimental study and particle flow modeling," Computers and Geotechnics, vol. 88, pp. 182-198, 2017.

[25] S. Yang, Y.-H. Huang, W.-L. Tian, and J. Zhu, "Erratum to: an experimental investigation on strength, deformation and crack evolution behavior of sandstone containing two oval flaws under uniaxial compression [Eng. Geol. (2017) 217: 35-48]," Engineering Geology, vol. 226, pp. 326-327, 2017.

[26] S. Y. Wang, L. Sun, C. Yang, S. Q. Yang, and C. A. Tang, "Numerical study on static and dynamic fracture evolution around rock cavities," Journal of Rock Mechanics and Geotechnical Engineering, vol. 5, no. 4, pp. 262-276, 2013.

[27] L. Shiyu, Introduction to Rock Fracture Mechanics, University of Science and Technology Press, Cambridge, MA, USA, 2010.

[28] Y.-H. Huang, S.-Q. Yang, and J. Zhao, “Three-dimensional numerical simulation on triaxial failure mechanical behavior of rock-like specimen containing two unparallel fissures," Rock Mechanics and Rock Engineering, vol. 49, no. 12, pp. 4711-4729, 2016.

[29] R.-h. Cao, P. Cao, H. Lin, C.-z. Pu, and K. Ou, "Mechanical behavior of brittle rock-like specimens with pre-existing fissures under uniaxial loading: experimental studies and particle mechanics approach," Rock Mechanics and Rock Engineering, vol. 49, no. 3, pp. 763-783, 2016. 
[30] S.-Q. Yang, W.-L. Tian, Y.-H. Huang, P. G. Ranjith, and Y. Ju, "An experimental and numerical study on cracking behavior of brittle sandstone containing two non-coplanar fissures under uniaxial compression," Rock Mechanics and Rock Engineering, vol. 49, no. 4, pp. 1497-1515, 2016.

[31] Y. Wang, X. Zhou, and X. Xu, "Numerical simulation of propagation and coalescence of flaws in rock materials under compressive loads using the extended non-ordinary statebased peridynamics," Engineering Fracture Mechanics, vol. 163 , no. 6, pp. 248-273, 2016.

[32] M. Sagong and A. Bobet, "Coalescence of multiple flaws in a rock-model material in uniaxial compression," International Journal of Rock Mechanics and Mining Sciences, vol. 39, no. 2, pp. 229-241, 2002.

[33] R. H. C. Wong, "Analysis of crack coalescence in rock-like materials containing three flawsF Part I: experimental approach," International Journal of Rock Mechanics and Mining Sciences, vol. 38, no. 7, pp. 925-939, 2001.

[34] C. H. Park and A. Bobet, "Crack initiation, propagation and coalescence from frictional flaws in uniaxial compression," Engineering Fracture Mechanics, vol. 77, no. 14, pp. 27272748, 2010. 